\title{
Reflections on the Teaching Reform of Basic Subjects in College of Ethnic Areas Based on the Flipped Classroom
}

\author{
Yahong $\mathrm{Li}^{1 \text {, a }}$, Aimin Song ${ }^{2, \mathrm{~b}}$ \\ ${ }^{1}$ College of Chinese, Gansu normal university for nationalities, Gannan, 747000, China; \\ ${ }^{2}$ College of mathematics, Gansu normal university for nationalities, Gannan, 747000, China. \\ avivid-0301@163.com, bsongaimin@163.com
}

Keywords: Colleges in ethnic areas; Flipped Classroom; Teaching Reform.

\begin{abstract}
In recent years, the implementation of "Flipped Classroom" has become an active exploration and effective attempt in the reform of college education in China. Since the gradual promotion of the "Flipped Classroom" teaching model in higher education institutions in China, some ethnic colleges have begun to experiment with this new education reform. This article will combine the reality of colleges in ethnic minority areas, trying to explore the necessity and feasibility of using "Flipped Classrooms" in the basic disciplines of colleges in ethnic areas, and give an effective reference to carry out the teaching reform of "Flipped Classroom" in colleges in ethnic minority areas.
\end{abstract}

\section{Introduction}

"Flipped Classroom", also known as "reverse classroom" or "upside down classroom", refers to under the information environment, teachers are providing teaching videos as the main form of learning resources, students complete the teaching of video prior to class learning resources by watching and learning. Then, eachers and students in the classroom to complete the homework question and answer, collaborative exploration and interactive activities such as a new teaching model[1]. The technical embryonic stage of the "Flipped Classroom" originated in 1996 and from Maureen J. Lage and Glenn J. Platt, coached by the University of Miami Business School in the United States. They first proposed " Flip the classroom, "the basic ideas and ideas, and conducted experiments in their universities, but did not spread. In April 2000, Wesley J. Baker constructed the Model of Classroom Flipping[2]. In fact, it is generally believed that the concept of flip classroom is widely promoted and generally the first high school teachers who considered turning the classroom Jonathan Bergmann and Aaron Sams, having their first thought of PPT for students who were unable to attend normal classes due to illness screen shots, accompanied by voice interpretation, but later found that other students can normally enroll in the video also studied. Therefore, they have promoted this teaching method. Since 2012, some scholars have introduced the new teaching method of "Flipped Classroom" into China and turning into a hot topic in education reform. From the search of Baidu for 10,000,000 results of "Flipped Classroom", it can be reflected to some extent Private attention; from "CNKI" to retrieve the "Flipped Classroom" papers, we find that only 23 before 2012, but now only published in 2016 year, a total of 7831 theses, which fully reflects the academic community of China of concern; on the "Flipped Classroom" search, 2016 published a total of 2060 related papers (known network retrieval), which to some extent, reflects the attention of domestic and foreign research. Almost all the universities and colleges in the Mainland have carried out the education and teaching reform based on "Flipped Classroom" in the past years. "Flipped Classroom" has so far received unprecedented attention, almost become the future of China's education reform.

In essence, the mode of "Flipped Classroom" teaching combines the advantages of traditional teaching methods and the advantages of networked teaching. It not only gives the leading role of teachers as a guider, enlightening and monitoring the teaching process, but also fully reflects the initiative, enthusiasm, and motivation of students as the main body in the learning process[3]. "Flipped Classroom" teaching mode subverts the traditional teaching process of "teacher teaching \& 
student homework \& examination". Teachers' main work is changed into promoting the internalization of students' knowledge through classroom teaching, and focusing on improving students' self-learning ability and innovation ability. Then teachers in classroom will spend most of their time listening to students' learning reports, answering questions, discussing issues and deepening their in-depth exchanges with teachers and students. In addition, for teaching difficulties or priorities, appropriate reinforcement in the classroom.

System theory examines the existence and development of the organization within the system from the interaction between the systems and the interaction between the system and the periphery as well as the internal environment. The organizations in the same system are different in the external environment, showing a different shape. Although universities located in ethnic areas belong to the same type of organizations as the mainland universities, but because of there are big differences in the external environment such as politics, economy and culture in the areas where the universities in the region are located, resulting in the functions of running a school and the orientation of running a school own unique properties[4]. Therefore, the education and teaching reform of "Flipped Classroom" model in colleges and universities in ethnic minority areas has great differences from the universities in the mainland. It is precisely due to this special external factor in ethnic areas. At the same time, our country is a country where many ethnic groups gathering together. The economic and social development of the ethnic agglomeration area plays a decisive role in national unity. Universities set up in ethnic enclaves are an important force for promoting economic development and social stability and unity in the ethnic enclaves. How to carry out the education and teaching reform in higher education institutions in areas where ethnic minorities are congregated, so that they can make better contributions to the economic development and social stability in ethnic areas, which is the primary consideration for educators in every ethnic areas.

\section{The Teaching of Basic Subjects in Minorities Colleges and the Characteristics of Minority Students}

Recently, based on the equality of the Internet and the constant improvement of infrastructure construction in ethnic areas, ethnic universities in the ethnic areas can enjoy the same network resources as the universities in the Mainland. However, due to the geographical location of ethnic regions and the self-learning ability of ethnic minority college students, the new mode of "Flipped Classroom" and educational reforms, especially in the basic disciplinary level, often has a large difference, which is mainly reflected in the following aspects.

Relative to university students in mainland, ethnic minority students have a low starting point of knowledge and relatively poor self-learning ability. Generally speaking, since universities in ethnic minorities are mainly enrolled as minority college students and permanent residents of Han nationality, and their admission scores are generally much lower than those of general undergraduate students, this means that in general, university students in ethnic areas have poor academic performance and low starting point in knowledge. At the same time, the traditional ethnic areas, especially in the northwestern region, are mainly engaged in nomadic income. Minority students are not open-minded, not good at meticulous study and poor at self-restraint. This is in contrast with the requirement of "Flipped Classroom" that students have strong autonomy learning ability has a certain gap. At the same time, ethnic minority college students are relatively more cautious relative to mainland students, who are more likely to advocate authority and can not easily express their own opinions. But generally, this is also related to students' lower professional abilities. Of course, college students from ethnic minorities also share the same characteristics with mainland college students: they are curious, gain knowledge through networks and love social networks.

Compared with the more open running environment in universities of mainland, the operating environment in higher education institutions in ethnic areas are relatively closed, and the overall level of teaching in teachers is low. As ethnic areas are generally more obstructed, universities in ethnic areas are relatively closed to the mainland, and unable to effectively integrate and communicate with advanced educational concepts in a timely and effective manner. However, university teachers in 
ethnic areas lacked the mastery and interest in the latest educational technologies and educational methods. This is mainly reflected in:

In terms of teaching methods, although various multimedia technologies have been widely introduced in higher education institutions in ethnic areas, the traditional "full house" teaching inertia has not escaped. However, the teaching method is changed from "chalk + blackboard" to "computer + big screen projection". Then, if we analyze deeply, we can see that its essence is still purely knowledge instillation. just the form of instilling is changed from the teacher's "oral instillation "into a technical" multimedia instillation "[5]. Throughout the teaching process, students are still the learning process that was tired of information bombing, and have not been able to exert their own autonomy at all.

Lacking of interaction between teachers and students. The current pervasive phenomenon is that in teachers' face-to-face teaching, teachers are basically full of lectures that fill the entire classroom, seldom interact with students. In the same time, students have few questions in class. In addition, since most teachers will integrate electronic Courseware on the online teaching platform, many students rarely take notes, listening is not very serious. In online learning, because of the separation of time and space, teachers are not easy to supervise and manage learners' learning behaviors and learning progress [6]. When students find problems in their own learning process, they can communicate with their classmates or teachers less through online teaching platform , or only some shallow communication, under this circumstance teachers will find it difficult to get the feedback of students.

Comparing with the mainland universities, the hardware environment in universities in ethnic areas is similar, but the hardware and equipment used by students in "Flipped Classroom" are deficient. The level of hardware: The construction of hardware facilities in universities in ethnic regions has basically met the demand of "Flipped Classroom" construction. However, the minority families in ethnic areas have poor family conditions and lack of effective facilities.

\section{Reflections on the Implementation of "Flipped Classroom" Teaching Modes in Basic Discipline Teaching in Universities in the Ethnic Agglomeration Areas}

The changes of teachers. The teachers in universities in the ethnic areas should make the following changes in the process of building "Flipped Classroom". First of all, in previous teaching, teachers assumed a relatively simple task of teaching, less involved in the internalization of the imparted knowledge, and the major difficulties encountered by students in learning were actually internalized produced during the process. It is also in the process of internalization, as many students grasp the watershed. In the context of flip classroom, teaching mode from static to dynamic process, teaching there are more "variables", therefore, in the "Flipped Classroom" model requires that teachers in universities in ethnic areas more participation in knowledge internalization.

Secondly, comparing with the traditional classroom-based teacher-led classroom teaching, it is necessary to turn it into a "dual-led" situation in the construction of "Flipped Classroom", and the knowledge transfer mode of the classroom is reversed, and the teacher prepares the pre-lesson video before the course, the main energy will focus on the effective organization discussed in the classroom, and this organizational form will be more focused on the individual learning feedback. The teachers will feedback some of the questions raised by active participants. Students have basically mastered the main tasks of teaching through video learning before class. So in the process of internalizing knowledge (that is, in the classroom), students have formed a positive exploration and a teacher-led question and answer.

Finally, it is not necessary for every course to be organized according to the course organization of the "Flipped Classroom", it is not necessary to increase students' burden and will not become an efficient classroom. The courses which are difficult and can not be done within the stipulated teaching time, To the effective extension of the basic courses for follow-up courses have a fundamental role in supporting the curriculum, campus public courses, you can do the best sharing of teaching resources. 
The change of students in "Flipped Classroom" reform.At present, compared with the students from the mainland, the minority college students have poor ability of independent thinking, autonomous learning needs to be strengthened, the individual's ability to independently research and solve problems, and the innovation ability need to be nurtured. In this kind of background, the classroom as itself the innovation of educational innovation has been highly sought after by universities in the ethnic areas. Moreover, the ability of turning the classroom into focus on cultivating students' autonomous learning, independent inquiry and inquiry learning during the course of learning, which is also the main point to turn the classroom teaching mode into constant emphasis.

\section{Other Issues to be Aware of}

Universities in ethnic areas are mainly teaching-oriented universities. The workload of teachers in such universities is large, and they have to undertake a great deal of teaching and student management tasks every day. The essence of "Flipped Classroom" is a meticulous operation of teaching. It requires a lot of work before class and after class, at the same time, it is necessary to master each student's nervousness and mastery of class actively, under such circumstances. If teachers are faced with a large teaching task, going to carefully design each course, it is very apt to cause the teacher's teaching weakness. Therefore, how to effectively turn over the teaching reform in the classroom has very high requirements on the designers of teaching reform.

In the course of "Flipped Classroom" teaching in basic subjects of universities in ethnic areas, it is more important, in essence, more challenging to stimulate students' enthusiasm for learning than to impart knowledge. We should pay attention to cultivating the ability of deepening comprehension and giving top priority to the undergraduates of ethnic minority students instead of mechanical training. Teachers should not be condescending, but should help their students to progress and change their roles like their friends. Sometimes their interest in learning can increase to the incredible help.

Generally speaking, we should not constrained by the fixed patterns in "Flipped Classroom", which is particularly worth tweaking for classroom practitioners for thinking and learning. In the implementation of "Flipped Classroom" can not be because this is a new teaching mode to appear "follow the trend" situation, regardless of the actual factors, blindly in each lesson to flip teaching. When it comes to flip teaching, we need to take account of the adaptability of disciplines, the different teaching methods adopted in different disciplines, and the characteristics of students. At the same time, we must also note that despite the education sector generally believes that "Flipped Classroom" education and teaching reform is in line with China's general direction of education reform, but should also be mainly to flip the class the following problems: innovation is not strong, in fact, literature[2] is not only a kind of minimal innovation for "Flipped Classroom" and the traditional education mode, but not a fundamental change from the traditional education mode. However, in any case, turning the classroom as a new teaching mode at present innovation, has its superior side, all schools with specific practical reform, which will bring a lot of innovation.

\section{Acknowledgements}

This work was supported by the 2016 innovation and entrepreneurship teaching achievement project nurturing program of Gansu normal university for nationalities "based on college and department basic discipline innovation and entrepreneurship education, training platform for construction and research"; The Scientific Research Foundation of the Higher Education Institutions of Gansu Province, China (Grant No. 2017A-139).

\section{References}

[1]. Zhong X, Song S A, Jiao L. Instructional Design Based on the Idea of the Flipped Classroom in ICT Environment [J]. Open Education Research, 2013. 
[2]. Rong Mei, Peng Xue hong. A study on the history, current situation and application of "Flipped Classroom”[J]. China Educational Technology, 2015(7):108-115.

[3]. He Kehang. The new development of educational technology theory frombBlendinglLearning [J]. China Educational Technology, 2004(3):21-31.

[4]. Zhang Junzong, The functions and the approaches of school management for colleges and universities in minorities areas [J]. Journal of Higher Education, 2009(7):31-35.

[5]. Ao qian, Liu hua, Jia de shan. Research on "Case - Task" Driving Teaching Model under Mixed Learning [J]. Modern Educational Technology, 2013, 23(3):122-126.

[6]. Guo Guanping, Zhang Xiaoning. The model building of blended learning based on the ecological perspective[J]. Modern Educational Technology, 2013, 23(5):42-46.

[7]. Guo Zhihua, Gao Guizhen, Wang Hongyan. Local undergraduate college Flipped Classroom teaching mode under the network environment[J]. Yinshan Academic Journal: Natural Science Edition, 2017, 31(3). 